\title{
Expression of $\alpha 2,6$-sialic acid-containing and Lewis-active glycolipids in several types of human ovarian carcinomas
}

\author{
KYOKO TANAKA $^{1}$, MIKIO MIKAMI ${ }^{2}$, DAISUKE AOKI ${ }^{1}$, \\ KAZUSHIGE KIGUCHI $^{3}$, ISAMU ISHIWATA ${ }^{4}$ and MASAO IWAMORI ${ }^{5}$ \\ ${ }^{1}$ Department of Obstetrics and Gynecology, School of Medicine, Keio University, Tokyo 160-8582; \\ ${ }^{2}$ Department of Obstetrics and Gynecology, School of Medicine, Tokai University, Kanagawa 259-1193; \\ ${ }^{3}$ Department of Obstetrics and Gynecology, St Marianna University School of Medicine, Kanagawa 216-8511; \\ ${ }^{4}$ Ishiwata Gynecologic Hospital, Ibaraki 310-0041; ${ }^{5}$ Department of Biochemistry, \\ Faculty of Science and Technology, Kinki University, Osaka 577-8502, Japan
}

Received June 30, 2010; Accepted August 31, 2010

DOI: $10.3892 / \mathrm{ol} .2010 .171$

\begin{abstract}
To identify glycolipid antigens associated with histologically defined types of ovarian carcinomas, we determined the amounts of $\alpha 2,6$-sialyl and Lewis-active glycolipids, the specific activities of the $\alpha 2,3$ - and $\alpha 2,6$-sialyltransferases, and the gene expression of sugar transferases in mucinous and serous cystadenocarcinoma, clear cell adenocarcinoma and endometrioid carcinoma tissues and cell lines derived from them. $\alpha 2,6$-sialyl glycolipid IV ${ }^{6} \mathrm{Neu} A c \alpha-\mathrm{nLc}_{4}$ Cer detected with a newly developed monoclonal antibody, Y916, was present in 5/7 serous cystadenocarcinoma cases in relatively higher amounts than those in the other carcinoma tissues. On the other hand, the amounts of Lewis-active glycolipids in serous cystadenocarcinoma tissues were lower than those in the other carcinoma tissues. No correlation was observed between the structures of Lewis glycolipids and the histological classification. The gene expression of $\alpha 2,3$ - and $\alpha 2,6$-sialyltransferases and $\alpha 1,3 / 4$-fucosyltransferase for the synthesis of Lewis-active glycolipids was not positively correlated with the amounts of the respective glycolipids, probably due to the epigenetic regulation of transferases in the overall metabolic pathways for lacto-series glycolipids. However, the amounts of GM3 and GD3 with short carbohydrate chains correlated with the relative intensities of GM3 and GD3 synthase gene expression, respectively. Among ovarian carcinoma-derived cell lines, the serous cystadenocarcinoma-derived ones exhibited a lower frequency of Lewis-active glycolipid expression than the other carcinoma-derived ones, which was similar to that
\end{abstract}

Correspondence to: $\mathrm{Dr}$ Masao Iwamori, Department of Biochemistry, Faculty of Science and Technology, Kinki University, 3-4-1 Kowakae, Higashiosaka, Osaka 577-8502, Japan

E-mail: iwamori@life.kindai.ac.jp

Key words: gangliosides, glycolipids, blood group, ovarian cancer, serous cystadenocarcinoma, tumor-associated antigen in the respective tissues. Thus, malignancy-related Lewisactive glycolipids were shown to be regulated in different modes in ovarian serous cystadenocarcinomas and the other carcinomas.

\section{Introduction}

Transformation-associated alteration of the carbohydrate structures in cellular glycoconjugates, including glycolipids and glycoproteins, occurs frequently in various types of cancer, mainly due to the aberrant expression of glycosyltransferases (1). Detection of these structures, including sialyl lacto-Nfucopentaose (CA19.9, sialyl Lewis a), in sera was successfully applied for the clinical diagnosis of epithelial cancer in gynecologic tissues and the digestive tract (2). However, in comparison to CA125, whose frequency in ovarian carcinomas is higher than that of CA19.9, and the level of which is used for preoperative surgical counseling and planning, the clinical usefulness and cell biological properties of ovarian cancers with CA19.9-carbohydrates have not been clearly elucidated yet (3). Since a number of carbohydrate structures were shown to play a role in the ligands of animal lectins, such as NeuAca26Gal/1-4GlcNAc for CD22 (4), sialyl $\mathrm{Le}^{\mathrm{X}}$ for P-selectin (5) and sialyl 6-sulfo-Le ${ }^{\mathrm{X}}$ for L-selectin (6), the expression of these structures and their modifications may affect the lectinmediated adhesion related to the invasion and metastasis of cancer cells. Transfection of the $\alpha 1,2$-fucosyltransferase gene into RMG-1 cells resulted in increases in $\mathrm{Le}^{\mathrm{Y}}$ and $\mathrm{H}-1$ glycolipids, and a concomitant decrease in sialylated glycolipids. The transfectants exhibited increased adhesion with mesothelial cells and resistance against an anticancer drug, 5-fluorouracil, in comparison to those of RMG-1 cells $(7,8)$. In addition, significant changes in glycolipids including Lewis-active ones were observed in ovarian carcinoma-derived KF28 cells exhibiting anticancer drug-resistance to cisplatin and taxol, probably due to an alteration of the activities of transporter proteins in regard to the excretion of drugs in glycolipid-rich membrane rafts $(9,10)$. These findings showed that the expression of fucosylated glycolipids exhibiting 
Lewis- and $\mathrm{H}$-antigenecities is closely correlated to the malignancy of cancer cells, including increased dissemination, metastatic potential and anticancer drug-resistance. However, since Lewis-active glycolipids are constructed of more than five carbohydrates, synthesis occurs through more than five glycosyltransferase reactions, whose activities are regulated by various epigenetic factors, including the concentrations of sugar nucleotides and acceptor glycolipids, $\mathrm{pH}$ and divalent cations. Notably, glycolipids in each step of the sequential multi-step reaction serve as substrates for the following step, suggesting that glycosyltransferase reactions determine the overall profile of glycolipids, including cancer-associated ones. Accordingly, the glycolipids in tissues from patients with ovarian carcinomas and cell lines derived from them were quantitatively determined in order to clarify their histologic classification-associated alterations, including Lewis-active ones, and to apply them as molecular markers for determining the malignancy of ovarian carcinomas, similar to those for colorectal carcinomas $(11,12)$.

\section{Materials and methods}

Tissue specimens. Histologic classification of the ovarian cancers was performed using criteria defined by the World Health Organization. The serous (7 cases) and mucinous (6 cases) cystadenocarcinoma, clear cell adenocarcinoma (3 cases) and endometrioid carcinoma (3 cases) tissues were obtained from the National Saitama Hospital. Written informed consent to use the specimens in this study was obtained from the patients, and the experimental protocol was approved by the local ethics committee.

Cell lines derived from ovarian cancers. The cell lines used in this experiment were obtained from patients with the following ovarian cancers: HAC-2 and RMG-1 from clear cell adenocarcinomas, 2008 and KF28 from serous cystadenocarcinomas, HMKOA from mucinous cystadenocarcinomas and HNOA from endometrioid carcinomas. The cell lines were cultured in Dulbecco's modified Eagle's medium (Nissui, Tokyo, Japan) supplemented with $10 \%$ fetal bovine serum (Nichirei Biosciences Inc., Tokyo, Japan) under a humidified atmosphere containing $5 \% \mathrm{CO}_{2}$ at $37^{\circ} \mathrm{C}$.

Materials. The glycolipids used in this experiment were purified from various sources in our laboratory: GM3 and $\mathrm{IV}^{3} \mathrm{NeuAc} \alpha-\mathrm{nLc}_{4} \mathrm{Cer}$ from human erythrocytes, GD3 from bovine brain, $\mathrm{Le}^{\mathrm{X}}$ from human fetal brain and $\mathrm{Lc}_{4} \mathrm{Cer}, \mathrm{Le}^{\mathrm{b}}$ and $\mathrm{IV}^{6} \mathrm{NeuAc} \alpha-\mathrm{nLc}_{4} \mathrm{Cer}$ from human meconium $(9,10)$.

Antisera. Monoclonal antibodies, Y916 and 5h6, were prepared by the immunization of mice with gangliosides from bovine milk and $\mathrm{IV}^{3} \mathrm{NeuAc} \alpha-\mathrm{nLc}_{4} \mathrm{Cer}$ from human erythrocytes, respectively, and the hybridization of lymphocytes with myeloma P3-X63-Ag8.653 in our laboratory $(13,14)$. As shown in Fig. 1, Y916 reacted with GD3 and $\mathrm{IV}^{6} \mathrm{NeuAc} \alpha-\mathrm{nLc}_{4} \mathrm{Cer}$, and $5 \mathrm{~h} 6$ with GM3, GD3 and $\mathrm{IV}^{3} \mathrm{NeuAc} \alpha-\mathrm{nLc}_{4} \mathrm{Cer}$, indicating that structural isomers, IV ${ }^{6} \mathrm{NeuAc} \alpha-$ and $\mathrm{IV}^{3} \mathrm{NeuAc} \alpha-\mathrm{nLc}_{4} \mathrm{Cer}$, are identified with Y916 and 5h6. Moreover, GM3 and GD3 were identified by their mobility on thin layer chromatograpy (TLC) and their reactions with Y916 and 5h6. The following

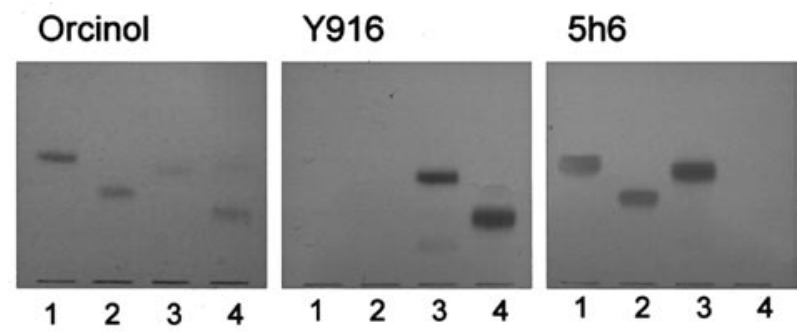

Figure 1. Thin layer chromatography (TLC) and TLC-immunostaining of glycolipids with monoclonal antibodies Y916 and 5h6. (1) GM3, (2) $\mathrm{IV}^{3} \mathrm{NeuAc} \alpha-n L c_{4} \mathrm{Cer}$, (3) GD3 and (4) $\mathrm{IV}^{6} \mathrm{NeuAc} \alpha-n L c_{4} \mathrm{Cer}$ were developed on plastic-coated TLC plates with chloroform $/$ methanol $/ 0.5 \%$ $\mathrm{CaCl}_{2}$ in water $(55: 45: 10$, by volume). Spots were visualized with orcinol$\mathrm{H}_{2} \mathrm{SO}_{4}$ reagent and monoclonal antibodies Y916 and $5 \mathrm{~h} 6$.

monoclonal antibodies were kindly donated: NCC-LU-279 for $\mathrm{Le}^{\mathrm{X}}$ and NCC-ST-433 for $\mathrm{Le}^{\mathrm{Y}}$ by Dr S. Hirohashi, National Cancer Center, Tokyo, Japan, MSN-1 for Le ${ }^{\mathrm{b}}$ by Dr S. Nozawa, Keio University, Tokyo, Japan, and 3C11 for sialyl Le by Dr $^{\text {a }}$ K. Matsumoto, Mikuri Immunol. Lab., Kyoto, Japan.

Analysis of lipids. The neutral and acidic glycolipids derived from the tissues and cells were examined by TLC and TLC-immunostaining with the development solvents, chloroform/methanol/water (65:35:8, by volume) for neutral glycolipids and chloroform/methanol/ $0.5 \% \mathrm{CaCl}_{2}$ (55:45:10, by volume) for gangliosides, as previously described $(10,13)$. Known amounts (0.1-1.5 $\mu \mathrm{g})$ of glycolipids, such as GM3, $\mathrm{Lc}_{4} \mathrm{Cer}, \mathrm{IV}^{3} \mathrm{NeuAc} \alpha-\mathrm{nLc}_{4} \mathrm{Cer}, \mathrm{IV}^{6} \mathrm{NeuAc} \alpha-n L c_{4}$ Cer and GD3, were developed on the same TLC plates for the preparation of standard curves. The densities of spots on TLC plates were determined by image analysis using NIH image.

$\alpha 2,3-$ and $\alpha 2,6$-sialyltransferases. The cancer tissues were homogenized using a homogenizer (Polytron; Kinematica, Luzern, Switzerland) in $0.25 \mathrm{M}$ sucrose, and the microsomal fractions were prepared by centrifugation as previously described (15). The standard assay mixture for microsomal $\alpha 2,3$ - and $\alpha 2,6$-sialyltransferases comprised $7.6 \mathrm{nmol} \mathrm{nLc}_{4} \mathrm{Cer}$, $10 \mathrm{mM} \mathrm{MgCl}_{2}, 5 \mathrm{mM} \mathrm{CaCl}{ }_{2}, 10 \mathrm{mM} \mathrm{CMP}$-sialic acid, $0.3 \%$ Triton CF54, $50 \mathrm{mM}$ 4-morpholinoethane sulfonic acid$\mathrm{NaOH}$ buffer ( $\mathrm{pH} 6.4)$, and $50 \mu \mathrm{g}$ enzyme protein, in a final volume of $50 \mu \mathrm{l}(16,17)$. After incubation at $37^{\circ} \mathrm{C}$ for $3 \mathrm{~h}$, the reaction was terminated with $100 \mu \mathrm{l}$ of ethanol. Then, $50 \mu \mathrm{l}$ aliquots of the solution were developed on two TLC plates with chloroform/methanol/ $0.5 \% \mathrm{CaCl}_{2}$ in water $(55: 45: 10$, by volume), detection being performed with $5 \mathrm{~h} 6$ for one and with Y916 for the other. Known amounts of $\mathrm{IV}^{3} \mathrm{NeuAc} \alpha-\mathrm{nLc}_{4} \mathrm{Cer}$ and $I^{6}{ }^{N} \mathrm{NeuAc} \alpha-\mathrm{nLc}_{4} \mathrm{Cer}(5-100 \mathrm{ng})$ were stained on the same plates, and the densities of the spots were determined by image analysis using NIH image. The amounts of endogenous gangliosides in the microsomes were subtracted from the values after the enzyme reactions.

RT-PCR analysis. Total RNA extracted from the tissues with Isogen (Nippongene, Toyama, Japan) was reverse-transcribed to cDNA with reverse transcriptase (M-MuLV; Takara, Kyoto, Japan) and oligo dT-primers, and then subjected to PCR with 0.5 units of Taq DNA polymerase (GoTaq; Promega, 


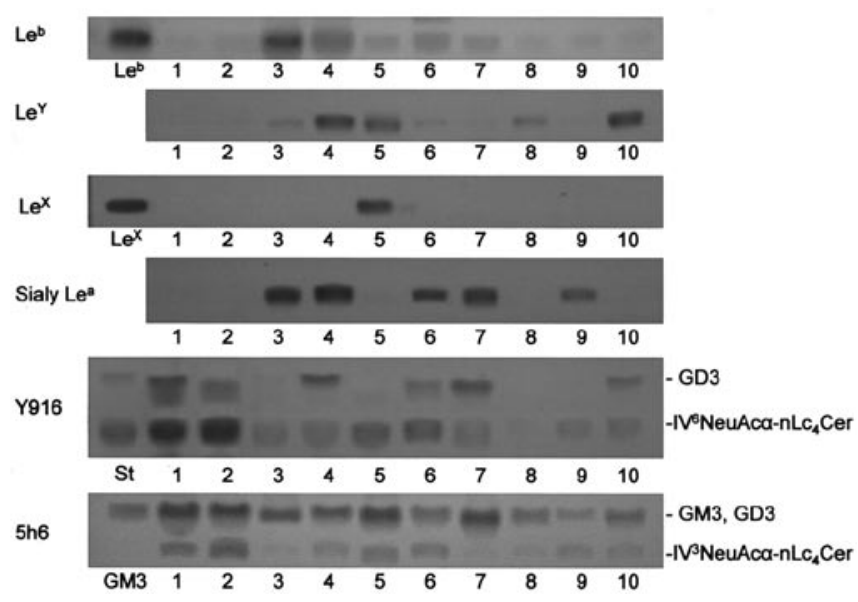

Figure 2. TLC-immunostaining of glycolipids from human ovarian carcinoma tissues. Glycolipids, corresponding to $0.2 \mathrm{mg}$ dry weight, were developed with chloroform/methanol/ $0.5 \% \mathrm{CaCl}_{2}$ in water (55:45:10, by volume). Spots were visualized by TLC-immunostaining with anti-Le ${ }^{\mathrm{b}}$, anti-Le ${ }^{\mathrm{Y}}$, anti-Le ${ }^{\mathrm{X}}$, anti-sialyl Lea and Y916 and 5h6 antibodies. The specimen numbers are the same as those shown in Table I. Standard glycolipids for Y916 was a mixture of GD3 and IV ${ }^{6} \mathrm{NeuAc} \alpha-\mathrm{nLc}_{4} \mathrm{Cer}$.

Kyoto, Japan) under the following conditions: LacCer sialyltransferase (GM3 synthase, AB018356), sense primer, atttgagcacaggtatagc, antisense primer, gatgtcaaaggcagtctct; GM3 sialyltransferase (GD3 synthase, D26360), sense primer, acaaatggaagactgctgcga, antisense primer, tggctctgt tcctgtcttcat; $\alpha 2,6$-sialyltransferase (BC031476), sense primer, tgcgtcctggtcttcttct, antisense primer, tctgcactgaacttgatgcc; 22,3-sialyltransferase (BC010645), sense primer, atctcccg ggaagacaggta, antisense primer, ccatgaagaaggggttgaga; and a1,3-fucosyltransferase 3 (FUT3, NM1097640), sense primer, tggtggctgtgtgtttcttc, antisense primer, ggctccaagttgaaccagat; 35 cycles of $95^{\circ} \mathrm{C}$ for $15 \mathrm{sec}, 54-64^{\circ} \mathrm{C}$ for $30 \mathrm{sec}$ and $72^{\circ} \mathrm{C}$ for $40 \mathrm{sec}$. The primers for glyceraldehyde 3-phosphate dehydrogenase (GAPDH) were used as controls. The resulting PCR products were electrophoresed on a $1.5 \%$ agarose gel, stained

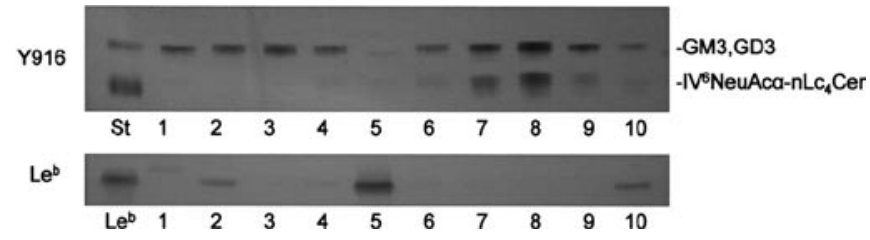

Figure 3. TLC-immunostaining of glycolipids from human ovarian mucinous and serous cystadenocarcinoma tissues. Glycolipids were obtained from an additional five specimens, respectively, i.e., other than those in Fig. 2 and Table I. The glycolipids, corresponding to $0.1 \mathrm{mg}$ dry weight, were used for TLC-immunostaining with monoclonal Y916 and anti-Le ${ }^{\text {b }}$ antibodies as described in Materials and methods. Standard glycolipids for Y916 was a mixture of GD3 and $\mathrm{IV}^{6} \mathrm{NeuAc} \alpha-\mathrm{nLc}{ }_{4} \mathrm{Cer}$.

with ethidium bromide, and examined using a UV transilluminator (15).

\section{Results}

Glycolipids in ovarian carcinoma tissues. Fig. 2 shows TLC-immunostaining of lipids from a number of ovarian carcinoma and uterine endometrial carcinoma tissues. In agreement with our previous results (7), Le ${ }^{\mathrm{b}}$ in mucinous cystadenocarcinomas was present in higher amounts than those in the other carcinomas (Table I). Among the Lewis glycolipids examined, $\mathrm{Le}^{\mathrm{b}}, \mathrm{Le}^{\mathrm{Y}}, \mathrm{Le}^{\mathrm{X}}$ and sialyl $\mathrm{Le}^{\mathrm{a}}$, whether one or a number of them, were detected in all tissues other than ovarian serous cystadenocarcinoma ones, in which they were not present or only in a trace amount. Alternatively, serous cystadenocarcinomas contained $\mathrm{IV}^{6} \mathrm{NeuAc} \alpha-n \mathrm{Lc}_{4} \mathrm{Cer}$ in significantly higher amounts than in the other carcinomas (Fig. 2). The amounts of $\mathrm{IV}^{6} \mathrm{NeuAc} \alpha-\mathrm{nLc}_{4} \mathrm{Cer}$ in serous cystadenocarcinomas were $>9$ times higher than those in the other carcinomas, while no significant differences were observed in the amounts of $\mathrm{IV}^{3} \mathrm{NeuAc} \alpha-n \mathrm{Lc}_{4} \mathrm{Cer}$ among the various types of ovarian carcinomas (Fig. 2 and Table I). The expression of $\mathrm{IV}^{6} \mathrm{NeuAc} \alpha-\mathrm{nLc}_{4} \mathrm{Cer}$ and $\mathrm{Le}^{\mathrm{b}}$ was further examined in an additional 5 cases of ovarian serous and mucinous cystadenocarcinomas, respectively. As shown in Fig. 3 and Table II,

Table I. Glycolipids in human ovarian carcinoma tissues.

\begin{tabular}{llccccccccc}
\hline No. & Histological classification & Specimen & Le $^{\mathrm{X}}$ & Le $^{\mathrm{Y}}$ & $\mathrm{Le}^{\mathrm{b}}$ & Sialyl Le & GM3 & GD3 & $\alpha 2,6$ & $\alpha 2,3$ \\
\hline 1 & Ovarian serous cystadenocarcinoma & 1 & - & - & - & - & 1.19 & 0.11 & 0.45 & 0.04 \\
2 & & 2 & - & - & - & - & 1.25 & 0.08 & 0.45 & 0.06 \\
3 & Ovarian mucinous cystadenocarcinoma & 1 & - & 0.01 & 0.53 & 0.04 & 0.54 & - & 0.01 & - \\
4 & Endometrial adenocarcinoma & 1 & - & 0.30 & 0.06 & 0.04 & 0.48 & 0.08 & 0.02 & 0.02 \\
5 & Ovarian endometrioid carcinoma & 1 & 0.09 & 0.09 & 0.02 & - & 1.33 & - & 0.04 & 0.03 \\
6 & & 2 & - & $\operatorname{tr}$ & 0.03 & 0.02 & 0.50 & 0.01 & 0.05 & 0.02 \\
7 & & 3 & - & - & 0.02 & 0.04 & 0.90 & 0.07 & 0.01 & $\operatorname{tr}$ \\
8 & Ovarian clear cell adenocarcinoma & 1 & - & 0.01 & 0.01 & - & 0.37 & - & - & $\operatorname{tr}$ \\
9 & & 2 & - & $\operatorname{tr}$ & 0.01 & 0.01 & 0.15 & $\operatorname{tr}$ & 0.02 & 0.01 \\
10 & & 3 & - & 0.20 & $\operatorname{tr}$ & - & 0.22 & 0.02 & 0.02 & 0.01 \\
\hline
\end{tabular}

The amounts of glycolipids are expressed as $\mu \mathrm{g}$ per mg dry tissue and are the means of three determinations by TLC-densitometry with the respective standard glycolipids. $\alpha 2,6, \mathrm{IV}^{6} \mathrm{NeuAc} \alpha-\mathrm{nLc}_{4} \mathrm{Cer} ; \alpha 2,3, \mathrm{IV}^{3} \mathrm{NeuAc} \alpha-\mathrm{nLc}_{4} \mathrm{Cer}$; tr, trace amount. Sample numbers correspond to those in Fig. 2. 
Table II. Amounts of IV ${ }^{6} \mathrm{NeuAc} \alpha-\mathrm{nLc}_{4} \mathrm{Cer}$ and $\mathrm{Le}^{\mathrm{b}}$ in ovarian serous and mucinous cystadenocarcinomas.

\begin{tabular}{|c|c|c|c|c|}
\hline No. & Histological classification & $\begin{array}{l}\text { Specimen } \\
\text { Case }\end{array}$ & $\alpha 2,6$ & $\mathrm{Le}^{\mathrm{b}}$ \\
\hline 1 & \multirow[t]{5}{*}{ Ovarian serous cystadenocarcinoma } & 3 & 0.06 & 0.01 \\
\hline 2 & & 4 & 0.23 & - \\
\hline 3 & & 5 & 0.37 & - \\
\hline 4 & & 6 & 0.11 & - \\
\hline 5 & & 7 & 0.01 & 0.13 \\
\hline 6 & \multirow[t]{5}{*}{ Ovarian mucinous cystadenocarcinoma } & 2 & - & 0.01 \\
\hline 7 & & 3 & - & 0.12 \\
\hline 8 & & 4 & - & 0.02 \\
\hline 9 & & 5 & 0.01 & 0.08 \\
\hline 10 & & 6 & - & 0.48 \\
\hline
\end{tabular}

The amounts of glycolipids are expressed as $\mu \mathrm{g}$ per mg dry tissue and are the means of three determinations by TLC-densitometry with the respective standard glycolipids. Sample numbers correspond to those in Fig. 3.

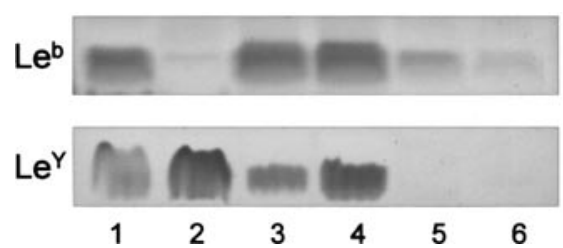

Figure 4. TLC-immunostaining of glycolipids from ovarian carcinomaderived cells. Glycolipids, corresponding to $0.2 \mathrm{mg}$ dry weight, were used for TLC-immunostaining with anti-Le ${ }^{b}$ and anti-Le ${ }^{\mathrm{Y}}$ antibodies. Lanes: 1, RMG-1; 2, HAC-2; 3, HMKOA; 4, HNOA; 5, 2008 and 6, KF28.

$\mathrm{IV}^{6} \mathrm{NeuAc} \alpha-n \mathrm{Lc}_{4} \mathrm{Cer}$ was present in 3/5 serous cystadenocarcinomas in amounts $>0.1 \mu \mathrm{g}$ per mg of dry weight, but not in mucinous cystadenocarcinomas. Conversely, $\mathrm{Le}^{\mathrm{b}}$ was detected in 4/5 mucinous cystadenocarcinomas and in one of the serous cystadenocarcinomas. Thus, the frequencies of expression of $\mathrm{IV}^{6} \mathrm{NeuAc} \alpha-\mathrm{nLc}_{4} \mathrm{Cer}$ and Lewis-active glycolipids were significantly high in serous cystadenocarcinomas and the other ovarian carcinoma tissues, respectively.

Glycolipids in ovarian carcinoma-derived cells. The expression of $\mathrm{IV}^{6} \mathrm{NeuAc} \alpha-n \mathrm{Lc}_{4} \mathrm{Cer}$ and Lewis-active glycolipids was examined in cell lines established from various types of ovarian carcinomas. Although $\mathrm{IV}^{6} \mathrm{NeuAc} \alpha-\mathrm{nLc}_{4} \mathrm{Cer}$ was not detected in any cell line, Lewis-active glycolipids were present in clear cell adenocarcinoma-derived RMG-1 and HAC-2, mucinous cystadenocarcinoma-derived HMKOA and endometrioid carcinoma-derived HNOA, in amounts higher than those in serous cystadenocarcinoma-derived 2008 and KF28. Their presence shows that relatively low and high amounts of Lewis-active glycolipids in serous cystadenocarcinomas and the other ovarian carcinoma tissues, respectively, are retained in the respective cell lines (Fig. 4).

Enzyme activities and gene expression of $\alpha 2,3-$ and $\alpha 2,6$ sialyltransferases in ovarian carcinoma tissues. To examine the enzymatic and genetic backgrounds of the expression of

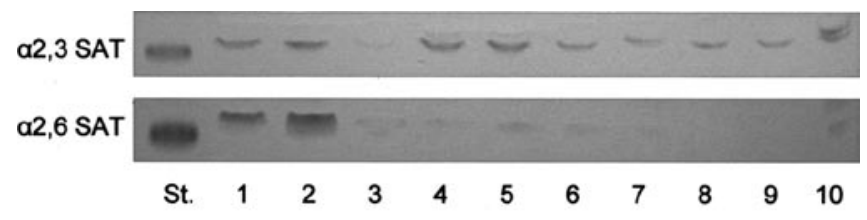

Figure 5. TLC-immunostaining of products following reactions of $\alpha 2,3$ - and $\alpha 2,6$-sialyltransferases (SAT). The products following the reactions with $50 \mu \mathrm{g}$ of enzyme proteins were developed with chloroform $/$ methanol $/ 0.5 \%$ $\mathrm{CaCl}_{2}$ in water (55:45:10, by volume), and detected by TLC-immunostaining with monoclonal antibodies 5 h6 for IV $^{3} \mathrm{NeuAc} \alpha-n L c_{4} \mathrm{Cer}(\alpha 2,3 \mathrm{SAT})$ and Y916 for IV ${ }^{6} \mathrm{NeuAc} \alpha-\mathrm{nLc}_{4} \mathrm{Cer}(\alpha 2,6 \mathrm{SAT})$, respectively. Standard glycolipids $\mathrm{IV}^{3} \mathrm{NeuAc} \alpha-\mathrm{nLc}{ }_{4} \mathrm{Cer}$ for $\alpha 2,3 \mathrm{SAT}$ and $\mathrm{IV}^{6} \mathrm{NeuAc} \alpha-n L c_{4} \mathrm{Cer}$ for $\alpha 2,6 \mathrm{SAT}$, respectively. The specimen numbers are the same as those in Fig. 2 and Table I.

$\mathrm{IV}^{6} \mathrm{NeuAc} \alpha-\mathrm{nLc}_{4} \mathrm{Cer}$ and Lewis-active glycolipids, the specific activities of $\alpha 2,3$ - and $\alpha 2,6$-sialyltransferases were determined by detection of the products, $\mathrm{IV}^{3} \mathrm{NeuAc} \alpha-\mathrm{nLc}_{4} \mathrm{Cer}$ and $\mathrm{IV}^{6} \mathrm{NeuAc} \alpha-\mathrm{nLc}_{4} \mathrm{Cer}$, and the gene expression by RT-PCR.

As shown in Fig. 5 and Table III, although the specific activities of $\alpha 2,3$-sialyltransferase with $\mathrm{nLc}_{4} \mathrm{Cer}$ as the substrate in the tissues were not correlated with the amounts of $\mathrm{IV}^{3} \mathrm{NeuAc} \alpha-\mathrm{nLc}_{4} \mathrm{Cer}$, or with the histological classification, those of $\alpha 2,6$-sialyltransferase were positively correlated with the relative amounts of $\mathrm{IV}^{6} \mathrm{NeuAc} \alpha-\mathrm{nLc}_{4} \mathrm{Cer}$ in the tissues, indicating that the high amounts of $\mathrm{IV}^{6} \mathrm{NeuAc} \alpha-\mathrm{nLc}_{4} \mathrm{Cer}$ in serous cystadenocarcinomas are due to the higher specific activity of $\alpha 2,6$-sialyltransferase. However, the $\alpha 2,3-$ and $\alpha 2,6$-sialyltransferase genes were ubiquitously expressed in all of the tissues examined and their relative intensities were not positively correlated with the enzymatic activities, or with the amounts of glycolipids (Fig. 6). Similarly, expression of the FUT3 gene encoding an $\alpha 1,3 / 4$ fucosyltransferase responsible for the synthesis of Lewis antigen was not correlated with the amounts of $\mathrm{Le}^{\mathrm{b}}, \mathrm{Le}^{\mathrm{X}}, \mathrm{Le}^{\mathrm{Y}}$ and sialyl Le $\mathrm{L}^{\mathrm{a}}$. In contrast to the gene expression of sugar transferases for neolacto-series glycolipids, the relative intensities of the GM3 and GD3 synthase genes were positively correlated with the amounts of GM3 and GD3 (Fig. 6). 
Table III. Specific activities of $\alpha 2,3$ - and $\alpha 2,6$-sialyltransferases with $\mathrm{nLc}_{4} \mathrm{Cer}$ as the substrate.

\begin{tabular}{ccc}
\hline No. & $\alpha 2,3$-sialyltransferase & $\alpha 2,6$-sialyltransferase \\
\hline 1 & 7.4 & 57.2 \\
2 & 8.5 & 105.2 \\
3 & 1.0 & 21.7 \\
4 & 11.6 & 12.4 \\
5 & 12.0 & 7.5 \\
6 & 5.5 & 10.9 \\
7 & 5.3 & nd \\
8 & 5.2 & nd \\
9 & 3.9 & nd \\
10 & 11.0 & 16.1 \\
\hline
\end{tabular}

Specific activities (pmol/100 $\mu \mathrm{g}$ of enzyme protein $/ \mathrm{h}$ ) are calculated from the amounts of products by TLC-immunostaining as shown in Fig. 5. Microsomes that served as the enzyme source were prepared from the same tissues as those in Table I and Fig. 2. nd, not detected.

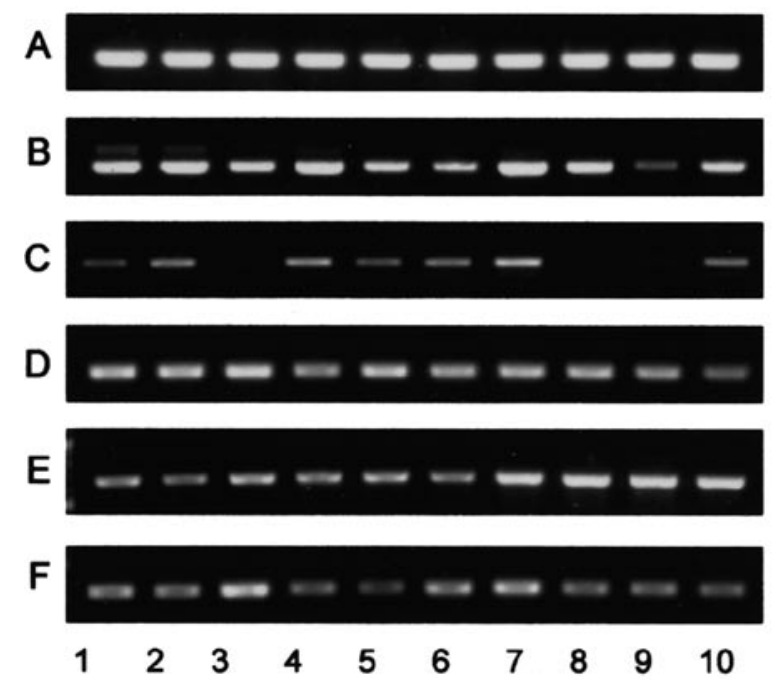

Figure 6. RT-PCR analysis of the glycosyltransferase genes in human ovarian carcinoma tissues. A, GAPDH; B, GM3 synthase; C, GD3 synthase; D, $\alpha 2,3$ sialyltransferase; E, $\alpha 2,6$-sialyltransferase and F, $\alpha 1,3 / 4$-fucosyltransferase 3. The specimen numbers are the same as those in Fig. 2 and Table I.

\section{Discussion}

Among ovarian carcinoma tissues with different histologic classifications, serous cystadenocarcinomas have been shown to express $\mathrm{IV}^{6} \mathrm{NeuAc} \alpha-\mathrm{nLc}_{4} \mathrm{Cer}$ at a higher frequency than the other carcinomas, and in compensation, the expression of Lewis-related glycolipids in serous cystadenocarcinomas was lower than in the other carcinomas. As shown in Fig. 7, since the syntheses of $\mathrm{IV}^{6} \mathrm{NeuAc} \alpha-\mathrm{nLc}_{4} \mathrm{Cer}$ and Lewis-active glycolipids occur with the same substrate at the branch of the lacto-series pathway, our findings suggest that the synthesis of lacto-series glycolipids is influenced by the availability of substrate glycolipids in individual steps of glycosyltransferase reactions. As reported in our previous paper (8), when the

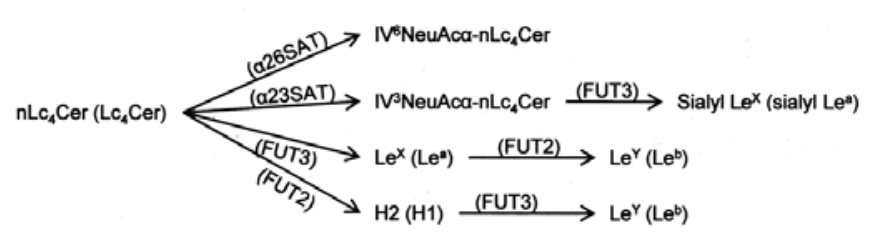

Figure 7. Metabolic pathways for the syntheses of $\mathrm{IV}^{6} \mathrm{NeuAc} \alpha-\mathrm{nLc}_{4} \mathrm{Cer}$ and Lewis-active glycolipids. SAT, sialyltransferase; FUT2, $\alpha 1,2$-fucosyltransferase; FUT3, $\alpha 1,3 / 4$-fucosyltransferase; $\mathrm{H}$, blood group $\mathrm{H}$ antigen.

activity of $\alpha 1,2$-fucosyltransferase in ovarian carcinoma-derived RMG-1 cells increased to 20-30 fold that in the original cells on transfection with the $\alpha 1,2$-fucosyltransferase gene, the amount of $\mathrm{Le}^{\mathrm{Y}}$ increased to 10-fold of the original level. On the other hand, sialylated glycolipids in the original cells, including sialyl $\mathrm{Le}^{\mathrm{X}}$ and $\mathrm{IV}^{3} \mathrm{NeuAc} \alpha-\mathrm{nLc}_{4} \mathrm{Cer}$, were absent in the transfectants, suggesting that the enhanced fucosylation of $\mathrm{Le}^{\mathrm{X}}$ and $\mathrm{nLc}_{4} \mathrm{Cer}$ at the terminal step of glycosylation inhibits their sialylation through deprivation of the substrate. Similarly, the high specific activity of $\alpha 2,6$-sialyltransferase in serous cystadenocarcinomas was considered to cause the increased amount of $\mathrm{IV}^{6} \mathrm{NeuAc} \alpha-n \mathrm{Lc}_{4} \mathrm{Cer}\left(\mathrm{Lc}_{4} \mathrm{Cer}\right)$ and the absence of the Lewis antigen due to the consumption of $\mathrm{nLc}_{4} \mathrm{Cer}\left(\mathrm{Lc}_{4} \mathrm{Cer}\right)$ for the syntheses of $\mathrm{Le}^{\mathrm{X}}\left(\mathrm{Le}^{\mathrm{a}}\right)$ by $\alpha 1,3 / 4-$ fucosyltransferase (FUT3), blood group H-glycolipid by $\alpha 1,2$-fucosyltransferase (FUT2) and $\mathrm{IV}^{6} \mathrm{NeuAc} \alpha-\mathrm{nLc}_{4} \mathrm{Cer}$ by $\alpha 2,3$-sialyltransferase $(\alpha 2,3 \mathrm{SAT})$, whose mRNAs were expressed in all of the tissues examined (18). Therefore, the epigenetic regulation of enzymatic activities in the individual steps of the neolacto- and lacto-series pathways may be involved in the determination of the mode of expression of sialylated and fucosylated glycolipids, including Lewis antigens, irrespective of the expression of glycosyltransferase mRNA. In contrast, the amounts of GM3 with shorter carbohydrate chains were closely correlated to the relative intensities of GM3- and GD3-synthase mRNAs, whose expression may directly lead to the active syntheses of GM3 and GD3 with a sufficient supply of substrate LacCer in proportion to their enzymatic activities. However, among ovarian carcinoma-derived cells, Lewis-related glycolipids were present in mucinous cystadenocarcinoma-, clear cell adenocarcinoma- and endometrioid carcinoma-derived cells in significantly higher amounts than in serous cystadenocarcinoma-derived cells, suggesting that the synthetic potential as regards to Lewis glycolipids in the tissues is maintained in the cultured cell lines. On the other hand, IV6 NeuAc $\alpha$ $\mathrm{nLc}_{4}$ Cer was present in 5/7 serous cystadenocarcinoma tissues in amounts of more than $0.1 \mu \mathrm{g}$ per mg dried tissue, while the amounts in the other carcinomas, if present, were less than $0.05 \mu \mathrm{g}$ per mg dry weight, indicating that the expression of $\mathrm{IV}^{6} \mathrm{NeuAc} \alpha-\mathrm{nLc}_{4} \mathrm{Cer}$ in serous cystadenocarcinomas occurs at a higher frequency than in the other carcinomas. In agreement with our results, the frequency of detection of

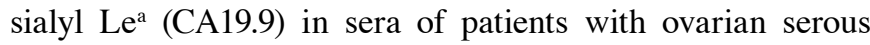
cystadenocarcinomas was reported to be low in comparison to those in the other carcinomas (3). In the case of a murine lymphoblastoid cell line, cells with $\mathrm{IV}^{6} \mathrm{NeuAc} \alpha-\mathrm{nLc}_{4} \mathrm{Cer}$ were shown to exhibit a low metastatic potential in comparison to those without it, probably due to the attenuated expres- 
sion of adhesion-related Lewis structures, due to enhanced $\alpha 2,6$-sialyltransferase activity (19). Transfection of the $\alpha 2,6$ sialyltransferase gene into cell lines with Lewis glycolipids is currently under investigation to demonstrate the modification of the Lewis glycolipid expression. In addition, since serous cystadenocarcinomas generally show a favorable prognosis, it can be suggested that $\mathrm{IV}^{6} \mathrm{NeuAc} \alpha-\mathrm{nLc}_{4} \mathrm{Cer}$ is a useful marker for the benign properties of cancer cells. To demonstrate the value of screening for $\mathrm{IV}^{6} \mathrm{NeuAc} \alpha-\mathrm{nLc}_{4} \mathrm{Cer}$ and Lewis-active glycolipids for the diagnosis of ovarian carcinomas, amounts of these glycolipids in sera of patients with serous cystadenocarcinomas are now being determined in comparison to those in tissues in our laboratory.

\section{References}

1. Roseman S: Reflections on glycobiology. J Biol Chem 276: 41527-41542, 2001.

2. Koprowski H, Herlyn M, Steplewski Z and Sears HF: Specific antigen in serum of patients with colon carcinoma. Science 212 53-55, 1981.

3. Canney PA, Wilkinson PM, James RD and Moore M: CA19-9 as a marker for ovarian cancer: alone and in comparison with CA125. Br J Cancer 52: 131-133, 1985.

4. Sgroi D, Varki A, Braesch-Andersen S and Stamenkovic I CD22, a B cell-specific immunoglobulin superfamily member, is a sialic acid-binding lectin. J Biol Chem 268: 7011-7018, 1993.

5. Springer TA and Lasky LA: Cell adhesion. Sticky sugars for selectins. Nature 349: 196-197, 1991.

6. Imai Y, Singer MS, Fennie C, Lasky LA and Rosen SD: Identification of a carbohydrate-based endothelial ligand for a lymphocyte homing receptor. J Cell Biol 113: 1213-1221, 1991.

7. Kiguchi K, Takamatsu K, Tanaka J, Nozawa S, Iwamori M and Nagai Y: Glycosphingolipids of various human ovarian tumors: a significantly high expression of $\mathrm{I}^{3} \mathrm{SO}_{3} \mathrm{GalCer}$ and Lewis antigen in mucinous cystadenocarcinoma. Cancer Res 52: 416-421, 1992.

8. Iwamori M, Tanaka K, Kubushiro K, Lin B, Kiguchi K, Ishiwata I, Tsukazaki $\mathrm{K}$ and Nozawa S: Alterations in the glycolipid composition and cellular properties of ovarian carcinoma-derived RMG-1 cells on transfection of the alpha1,2fucosyltransferase gene. Cancer Sci 96: 26-30, 2005.

9. Kiguchi K, Iwamori Y, Suzuki N, Kobayashi Y, Ishizuka B, Ishiwata I, Kita T, Kikuchi Y and Iwamori M: Characteristic expression of globotriaosyl ceramide in human ovarian carcinomaderived cells with anticancer drug resistance. Cancer Sci 97: 1321-1326, 2006.
10. Iwamori M, Iwamori Y, Kubushiro K, Ishiwata I and Kiguchi K: Characteristic expression of Lewis-antigenic glycolipids in human ovarian carcinoma-derived cells with anticancer drugresistance. J Biochem 141: 309-317, 2007.

11. Goupille C, Marionneau S, Bureau V, Hallouin F, Meichenin M, Rocher $\mathrm{J}$ and Le Pendu J: alpha1,2-Fucosyltransferase increases resistance to apoptosis of rat colon carcinoma cells. Glycobiology 10: 375-382, 2000.

12. Baldus SE, Hanisch FG, Pütz C, Flucke U, Mönig SP, Schneider PM, Thiele J, Hölscher AH and Dienes HP: Immunoreactivity of Lewis blood group and mucin peptide core antigens: correlations with grade of dysplasia and malignant transformation in the colorectal adenoma-carcinoma sequence. Histol Histopathol 17: 191-198, 2002.

13. Iwamori M, Takamizawa K, Momoeda M, Iwamori $Y$ and Taketani Y: Gangliosides in human, cow and goat milk, and their abilities as to neutralization of cholera toxin and botulinum type A neurotoxin. Glycoconj J 25: 675-683, 2008.

14. Lin B, Kubushiro K, Akiba Y, Cui Y, Tsukazaki K, Nozawa S and Iwamori M: Alteration of acidic lipids in human sera during the course of pregnancy: characteristic increase in the concentration of cholesterol sulfate. J Chromatogr B Biomed Sci Appl 704: 99-104, 1997.

15. Tanaka K, Kubushiro K, Iwamori Y, Okairi Y, Kiguchi K, Ishiwata I, Tsukazaki K, Nozawa S and Iwamori M: Estrogen sulfotransferase and sulfatase: roles in the regulation of estrogen activity in human uterine endometrial carcinomas. Cancer Sci 94: 871-876, 2003

16. Ikehara Y, Shimizu N, Kono M, Nishihara S, Nakanishi $H$, Kitamura T, Narimatsu H, Tsuji S and Tatematsu M: A novel glycosyltransferase with a polyglutamine repeat; a new candidate for GDlalpha synthase (ST6GalNAc V)(1). FEBS Lett 463: 92-96, 1999.

17. Yoshiki J, Kubushiro K, Tsukazaki K, Udagawa Y, Nozawa S and Iwamori M: High expression of uridine diphosphate-galactose: $\mathrm{Lc}_{3} \mathrm{Cer}$ beta 1-3 galactosyltransferase in human uterine endometrial cancer-derived cells as measured by enzyme-linked immunosorbent assay and thin-layer chromatographyimmunostaining. Jpn J Cancer Res 88: 669-677, 1997.

18. Weston BW, Nair RP, Larsen RD and Lowe JB: Isolation of a novel human alpha $(1,3)$ fucosyltransferase gene and molecular comparison to the human Lewis blood group alpha $(1,3 / 1,4)$ fucosyltransferase gene. Syntenic, homologous, nonallelic genes encoding enzymes with distinct acceptor substrate specificities. J Biol Chem 267: 4152-4160, 1992.

19. Lo NW, Dennis JW and Lau JT: Overexpression of the alpha2,6sialyltransferase, ST6Gal I, in a low metastatic variant of a murine lymphoblastoid cell line is associated with appearance of a unique ST6Gal I mRNA. Biochem Biophys Res Commun 264: 619-621, 1999. 